\title{
Keys for an Investigation into the Origins of the Communicative Methodology in Language Teaching
}

\author{
Aquilino Sánchez \\ Universidad de Murcia
}

\begin{abstract}
The historical study of how languages have been taught and lcarnt proves again and again that new methods are rarely found. It is more common to find the restatement of similar principles and/or ideas in a different way, closer to the context in which we are involved in each period of time (decade, century, etc.). It has usually been too quickly accepted, particularly since the end of the nineteenth century, that new methodologies will solve the tiresome task of learning foreign languages. According to this belief, the "latest method» is considered the ideal one, the "magic pill» that will substitute old and inefficient recipes. An analysis of the sources that underlie communicative methodology will try to illustrate how it is dependent on previous trends, linguistics, psychology and pedagogy. The understanding and shaping of a communicative methodology will certainly be easier if we go back to the roots and sources from which it emerged.
\end{abstract}

\section{The Teaching Scene}

As sanctuaries for the transmission of knowledge from generation to generation, schools have typically emphasized teaching rather than learning. This practice has helped the consolidation of the following pedagogic set up, widely present in academic institutions:

a. Teaching is centred on the «teacher.» $\mathrm{He}$ is the one that bears the responsibility of «teaching», of making knowledge available and accessible to the student. The student «learns» by means of the teacher or through the teacher. The underlying principle is: the teacher knows, the student doesn't. Evidently the process of teaching assumes that «there is somebody that wants to know something he doesn't know». Still, there are «two actors", and it would be unfair to concentrate on only one. After all, teaching is not a goal in itself, but a «means towards an end»: to prepare the way for the students to learn. Teachers are mediators, with no function if the students are not present. Accordingly they should not become the protagonists, but rather the «facilitators» of learning. Students, within this perspective, need to play a more significant role in the process. 
b. Teaching goals (what the learners should «learn») are determined by one of the participants in the process: the teacher. In the field of language teaching, those goals have largely been restricted to the area of grammar and vocabulary. Activities for teaching these contents were based on the specificity of the grammatical contents. They were also one-sided, in the sense that they took for granted that what really mattered was teaching rather than learning.

\section{Reconstructionism and Language Teaching}

This view, well established in the academic world, fits in well with some basic concepts and principles of western democracies. All citizens have the same right to education. Education, in fact, is the condition necessary for achieving more justice in society and better conditions of life. Governments engage in the task of guaranteeing everybody a basic education. The school system must be prepared for that. Curricula become an essential part of educational policy. One of the elements required to develop such an educational policy is the possibility of defining how much the citizens must learn in order to be considered «basically educated.» Pedagogues and planners enter the governmental bureaucracy and their job is to construct curricula based on objectives that could later be objectively evaluated and measured. The result is an approach generally referred to as an «ends-means» approach. It has one main advantage for governmental planners: it offers the possibility of quantifying what you must teach and learn and therefore it makes it easy to take decisions on when and how the members of a society have achieved the educational goals predefined by the authorities.

Taba (12) gives a very clear description of the development of an «ends-means curriculum»:

Step 1: Diagnosis of needs

Step 2: Formulation of objectives

Step 3: Sclection of content

Step 4: Organization of content

Step 5: Sclection of learning experiences

Step 6: Organization of learning experiences

Step 7: Determination of what to evaluate and of the ways of doing it

We are given a linear procedure for constructing the curriculum. Goals and the means to attain them must be conveniently related to one another. If goals are «behavioural patterns,» the educational process will be to create the «means» to reach them first and then consolidate them. Goals must therefore be as explicit as possible and avoid generalizations. Reconstructionism (as this approach is named) is welcomed by democratic governments as a way of implementing educational goals. Experts design curricula for the schools. It is important to stress the fact that those «experts» are far from being the elite that used to be responsicle for curricula in the past; they do not constitute an «elite that generates another eliê.» These experts work in their offices, produce rather neutral and aseptic reports and cannot think in terms of individuals, only of anonymous groups. Professionalism gains, even if it is true that some individual, subjective values cannot be taken into consideration here. 
The teaching of languages cannot be divorced from these trends in education. Curriculum design and the setting of teaching objectives is also the responsibility of governments. A superficial analysis of what was being taught in the sixties and how reveals that two essential features of reconstructionism were also to be found in the teaching of foreign languages. Audiolingualism, for example, combines

- a strict and clear selection of goals («ends»)

- with the «means» to reach them: behaviouristic practices

Some variants within the structural approach in language teaching (structuro-global, situational, audiovisual, etc.) do not change the basic methodological pattern.

In the early seventies we may again detect reconstructionist beliefs and values in the work and reports of the Council of Europe project no. 4 (1973) keeps close to Taba's definition of reconstructionist procedures. Among others, we point out some guidelines of the document:

- teaching necds are defined and selected after an «analysis of the communicative needs of the students»

- goals are determined by classifying linguistic components in ficlds that can be readily quantificd: functions, linguistic exponents, grammatical structures, vocabulary lists

Priority in the analysis is given not to grammar but to functions in the use of language. This is a significant step away from structural approaches.

Prior to the involvement of the Council of Europe in the field of teaching foreign languages is a project financed by the Nuffield Foundation, in England: a team of teachers worked for several years, in the sixties, on the elaboration of a textbook for teaching German in schools (Vorwärts project). The authors selected linguistic items taking into account what students wanted or needed (expectations on the part of the learners). With that purpose in mind they investigated «speaker intentions», which they labelled «linguistic activities». As a result of their investigation they include linguistic materials for «apologizing, requesting information, expressing wishes. . .» (Peck). Those semantic areas are then followed by the linguistic elements through which that meaning is expressed. At the end of the book we find the list of words required to fulfill the communicative needs and functions specified earlier. Wilkin's notions and functions can hardly be dissociated from this investigation. Also within this trend may be considered the group of experts working for the Council of Europe on the project concerning the teaching of foreign languages. Trim (Some Possible Lines 9), director of this project, describes the goals in this manner:

We set out to identify a number of coherent but restricted goals relevant to the communicative needs of the learner. We then attempt to work out in detail the knowledge and skills which will equip the learner to use the language for the communicative purposes defined. In the light of his characteristics and resources we have then to establish a feasible learning programme leading to the mastery of this body of knowledge and skills, and a means of testing and evaluation to provide feedback to all parties concerned as to the success of the programme. 
It is taken for granted that we can quantify the communicative needs of the learners. That will allow for an interchange of «unit/credits» among institutions adopting this scheme. Those units should reflect the specific communicative needs of particular groups of students. Such a system would favour a homogenization of programmes for teaching languages, as well as evaluation procedures leading to the granting of diplomas with wide acceptance. Trim gives more details on how such unit-credits should be constructed:

a. Determine what the learner will need to do in using the language for communication in the real life situations in which he is likely to be engaged

b. Calculate the knowledge and skills he will need to acquire in order to be able to act in the required way

c. On this basis, set out clear, operational learning objectives

d. Assess the characteristics of the learner

e. Survey the resources of the teaching institution and the constraints under which it operates

f. If necessary, modify objectives in the light of the analysis of resources

g. Plan the course in terms of the activities required of the learner (including progression and phasing of the objectives, methodology and roles of teacher and media)

h. Conduct the course, with continuous monitoring of the learner's progress

i. Evaluate the learner's achievement and the effectiveness of the courses

«Units,» as described by Trim, meet some conditions, particularly regarding the period required for their acquisition by learners and the adequacy of the content to the students' needs. Since goals in each one of these «units» are quantifiable, their transportability from one program to another is ensured. Still, to decide on the choice of linguistic needs, generalizations must be avoided and definitions have to be more specific than Richterich's (5) statement:

Définir des besoins de communication consistera à décrire ce qui manque à un individu ou à un groupe d'individus pour changer par une action langagière ou autre l'état de déséquilibre dans lequel il se trouve en ce moment.

Inasmuch as we can affirm that notional-functional syllabuses are reconstructionist in nature, their similarities to structural programmes are self-evident. That fact explains the lack of rupture with methodological issues and procedures in the previous decade. It is particularly interesting to analyse the kind of techniques and activities used in the new-born notional syllabuses: they fit into the same behaviouristic patterns of structural methodologies: linguistic structures (now called «linguistic exponents of language functions") and drills or repetition of those structures in connection with some topic areas or «notions.» It is true that the emphasis on the creation of materials now offered to the learner has shifted from purely grammatical or structural criteria to communicative, more meaningful or semantically based ones. Moreover, the inclusion in the curriculum of the communicative needs of the students favours this semantic approach and works against the exclusive protagonism of formal, grammatical elements in the classroom. At the same time, we can also affirm that the analysis of communicative needs, prior to the design and elaboration of a curriculum, is indebted 
to reconstructionist views in pedagogical sciences. After all, «needs» are not totally absent from teaching methods in earlier times. They were understood, however, in terms of «needs for learning a language depending on what it was necessary to know from the point of view of the formal/linguistic system.» Real communication or language use was not taken into consideration. It was assumed that once you had acquired the grammatical code, you were prepared to use the language in communication. Some factors, however, conditioned the application of purely formal criteria: linguistic structures and vocabulary selection were based on frequency lists derived from language use. As a result, the structures presented were not so far away from real communicative use as one might have expected. Even if the needs of the learners were not explicitly analysed in advance, they were present in the same degree and amount as the real linguistic usage was taken into account for the elaboration of frequency structural lists.

Both in the structural and notional-functional syllabuses the «ends-means» approach ends up with results which are similar in many features: goals are set without the direct intervention of the learners. Students must learn what is offered from outside themselves. In some ways, the objectives they must learn do not come from their own decision, they are outside the realm of their own will; consequently, the person is not in the best condition for the acquisition and integration of new knowledge. After all, the corpus of materials to learn are to be intimately connected to the personality of the student. Contextualization would be difficult to achieve keeping to reconstructionism. New developments were needed in order to engage the inner will of the learners in the process.

\section{Linguistics and Language Teaching}

Language teaching has been always closely related and dependent on linguistic thought and fairly disconnected from psychology and pedagogy. For that reason methods in language teaching have been heavily dependent on the theory of language in fashion at a specific period of time. Changes in language thought have shown their effects immediately on teachers and schools. Linguists or grammarians, however, are not specialists in psychology or pedagogy, as psychologists or pedagogues are not expert linguists either. We must assume that the history of language teaching has suffered from the absence of pedagogic and psychological insights into methods born among linguists, developed by linguists and put into practice by disciples of linguists.

It is to be acknowledged that changes in linguistic theory have a direct impact on methodologists, authors of textbooks and teachers of language. This has been a recurrent fact in the past and it was also present in the origins of the notional-functional approach. Criteria for the development of a communicative syllabus, described and advanced by Mumby, are essentially of a linguistic nature. Analytical studies on the characteristics of the communicative process affecting language teaching are carried out by linguists. Linguists are again the ones who give advice or suggest new methods for the application of the principles to the teaching scene (Candlin, Halliday Explorations, Language as Social Semiotics, Hymes «On Communicative Competence,» Canale, Widdowson, etc.). We can conclude that the most decisive factor in teaching methods has always been current thought on language. 
Some attempts were made to apply Chomsky's transformational theory of language to language teaching, but with little success. Structuralism was still quite strong in Europe in the sixties and seventies. English linguists, in particular, were strongly connected and indebted to the Firthian school of linguistics. The context is an important ingredient in linguistic analysis. Scholars such as Halliday and Lyons are excellent exponents of this view. Language is analysed not as a set of isolated elements (words, phrases), but rather looking at a wider context (sentence, paragraph, discourse). Meaning comes from the «whole» rather than from the «particular.»

Applied linguistics emerges as a strong field for investigation in the seventies. Sociolinguistics is a discipline in fashion for field investigations in language. Of special interest here are the analyses of «extralinguistic codes,» which are considered to be of extraordinary importance for a correct understanding of information in daily communication. Following those analyses, you can even say that language use would not be complete and could not be fully comprehensible if such extralinguistic codes were not taken into consideration. Hymes (278) claims that the absence of some of those rules of usage would invalidate grammatical rules or make them non-operative.

A superficial analysis of how communication takes place in a given situation illustrates the issue. Affective relationships between two or more persons, geographic and physical environment, gestures, situational context, social level at which communication takes place, distance between speakers, among other factors, are all of great importance; they can even replace or substitute grammatical forms concerning morphology, syntax, phonology and specific vocabulary items. Extralinguistic elements may therefore become a code in themselves for transmitting specific information; they are transformed into «adequation rules» in the sense that they are able to relate the linguistic message proper to variables external to it.

One must be careful when referring to «external» components. Sociolinguistics helps us to understand that extralinguistic elements such as the ones mentioned here, are external to the linguistic code, but not to the communicative process. We must therefore conclude that communication goes beyond the field of pure linguistic forms. Teaching language from a communicative point of view should not follow a similar restrictive path.

"Adequation rules» do not only participate as an essential part of the communicative act; they can even interfere with the meaning of linguistic forms and change their «normal, standard» value (what they would mean in a neutral environment). This reality counts for significant differences of some of those codes within social groups (nations, regions, towns, social levels, etc.). The insistence on inviting somebody for dinner is required in Spain to assure the guest that she/he is really invited (the invitation repeated only once might only be equivalent of a social gesture without further implications). The same procedure would be applied for accepting or declining such an invitation. The same behaviour would be interpreted differently in Great Britain, for example. The same word may suggest totally different meaning to the listener in different situations. A context may require linguistic elements (including syntax) which will not fit other contexts, in spite of the fact that it transmits the same information.

Non-linguistic elements are necessary for the correct development of communication. Their inclusion in the curriculum as teaching materials is a necessity rather than a whim. One of the most important requirements for curriculum planners is to present language in contexts of communication. Situations close to or imitating reality 
have been present in teaching materials since the Middle Ages. But a communicative approach will go beyond that: those situations should not be conditioned by the selection or inclusion of specific structures or vocabulary items prior to the situations themselves. Communicative situations must be functional from the beginning. In other words, it is communication what we are aiming at. Language is only instrumental in the process.

The development of curricula for language teaching changes a great deal within this perspective. Priority is given to communication instead of grammar or decontextualized linguistic forms. The methodology for building the curriculum is nonetheless basically reconstructionist. «Quantification» of the materials is there, aiming at situations that take context into account. Trim (Some Possible Lines 8-9) is clear in affirming that:

Sceing the role of language in adult life in this light gives a quite different perspective on language learning from the steady developmental progression envisaged in straight, through learning. In place of such generalized objectives as an «elementary», «intermediate» or «advanced» knowledge of a language, one looks to providing a learner with the body of knowledge and the skills he needs to solve a defined communication problem. These problems may be large or small. One may ask: How do I buy a metro ticket in Paris? The answer might be given just un billet or un carnet.... For a different way of life we can expect a different set of questions: How do I complain that my flat is damp? How do I deal with my landlord? . .

This new perspective leads us to the central idea of learning by units: to organize specific learning programmes to serve particular defined purposes.

«Units» for language teaching, as defined by Trim, are coherent and lead to defined communicative goals. Functionally useless language should be avoided following this strategy.

The development and consolidation of this approach to language teaching in the eighties (and probably in the nineties) has received permanent support and encouragement from current linguistic studies. Discourse analysis and pragmatics stress the need for more and more global contextualization in the correct analysis of language in use.

\section{Autonomous Learning}

Language teaching is essentially carried out by teachers with a philological, literary and/or linguistic background. The logical outcome of this is that what happens in the classroom is closely connected to and dependent on those disciplines. Furthermore, modern society favours intercommunication between different areas. Ideas «travel» quickly from one discipline to another. Such a possibility should be positive because connected disciplines may benefit one another. This is the case here.

Western society cannot relinquish democratic values and is extremely sensitive to them. The respect and consideration towards «others,» with equal rights, is essential in a democracy. Individuals should therefore be favoured, their inner development must be encouraged and promoted. Learners, as individuals, require a greater attention. After all, one might conclude, students of foreign languages have the right to increase and 
improve their learning capacity. Still more: the final goal of the teaching process and system is none other than the learners. Everything in the process has to be oriented towards that aim and conditioned to get the best results. Within this «mediatory» function we must include teachers and teaching materials, as well as the «means» used to attain the final objective. Once again, but this time starting from a different perspective, we come to a conclusion already mentioned before: teaching planned and brought from outside the learner, or without the potentiality of involving the student in a process which is strictly aimed at individuals, is weakened in its power: instead of putting to work all the elements involved in the teaching/learning situation, it diminishes the role of the learner by concentrating on the teacher. Even curricula that increase the role of activities, as well as the role of the teacher, but leave the learner in the «backyard», are essentially limited.

Autonomous learning aims precisely at promoting the role of the learner in the educational sphere. Holec (3), quoting Schwartz (Permanent Education), defines «autonomy» as «the ability to assume responsibility for one's own affairs.» If this principle is applied to language teaching, autonomous learning would equal «the ability to take charge of one's own learning.»

Of course, we are dealing here with an ability which everybody must acquire, usually through learning, because we are not born with it. The implications of autonomous learning are far reaching: the autonomous learner is responsible for his own learning. He must take the decisions and establish the means to achieve that goal. Holec (3), following Dieuzeide and H. Janne, specifies what this responsibility means:

- determining the objectives;

- defining the contents and progressions;

- selecting methods and techniques to be used;

- monitoring the procedure of acquisition properly speaking (rhythm, time, place, etc.);

- evaluating what has been acquired.

It is a highly demanding task and perhaps we cannot be too optimistic about its implementation by many learners even if we admit different degrees of «intervention» from outside. Somebody, for example, may support or help the student in building such a responsibility and so on. We must bear in mind that programmed teaching must not be equated with autonomous learning. The former only allows the student to take decisions on when and where to learn; the contents, methods and evaluation have been already laid down by somebody else.

It is not my aim here to enter into a more detailed analysis of the autonomous learner and learning. The issue, however, is attractive to many pedagogues and eventually to western thought, which usually tends to stress the values of the individual rather than the values of groups. In any case, the principles underlying autonomous learning work strongly in favour of the idea of giving more importance to the role the learner must play in the classroom and in the educational system.

We should not dissociate «autonomy in learning» from progressivism in pedagogy. «Progressivists» aim at learner-centred education as well. Again, this approach is well rooted in the past; Rousseau and Piaget are excellent and well-known exponents. Natural «growth» in education develops basically through experience. And one of the 
ingredients of these experiences is that they must be necessarily «personal»; they cannot be substituted by external programmes. The learners, we may conclude, learn as a result of their own efforts. Teachers however are not simple mediators, acting as instructors. They must help to create the conditions, the environment in which students may learn and be motivated to learn how to learn. Learning, progressivists affirm, is achieved only when the individual integrates into his own body of knowledge, other elements from outside. There is no possibility of integration without the filter of one's own experience. Rogers, a progressivist, puts it in this way:

The only man who is educated is the man who has learned how to learn; the man who has learned how to adapt and change; the man who has learned that no knowledge is secure, that only the process of seeking knowledge gives a basis for security.

Emphasis on the learner and his freedom to learn what he decides, has no doubt driven us to reject, sometimes only partially, academic and goal-centred curricula. The role of the teacher fades away. Still, a goal-free style of education does not necessarily eliminate the teacher; it might only change his function in the process. Progressivism, in fact, pursues open education, with no limits previously laid down in terms of contents, goals and procedures. Human knowledge is not a «closed system» and the school must adjust to the relative nature of human knowledge.

Programmes that try to rely on the way we learn more than on the goals we must achieve in learning, cannot be satisfied with reconstructionist curricula. A new concept of curriculum development is being put forward: the so called process approach. Such a curriculum will be designed on «principles of procedure», in order to guide the teachers in the process of teaching: they are the ones in charge of setting the process in motion. The participants and actors, however, must be the students. Let me quote some specifications of a «process curriculum design» advanced by Stenhouse (84ff):

- to initiate and develop in youngsters a process of question-posing; to teach a research methodology where children can look for information, etc.

- to conduct classroom discussions in which youngsters learn to listen as well as to express their own views; to encourage children to reflect on their own experiences.

- to create a new role for the teacher, in which he becomes a resource rather than an authority.

Predetermined «packages» would not fit this scheme. On the other hand, the kind of activities suggested and their design are of paramount importance because they affect the "process" in the classroom more and may favour the involvement of the student in the process (Parlett and Hamilton). Syllabuses modelled on the «Threshold Level» are questioned by progressivism. But they might be accepted as a «light» contribution to both teachers and students if they are accompanied by a set of exercises or activities along the lines we have been experiencing in the last few years in language teaching materials: activities centred on the process more than on the content. 


\section{Psycholinguistics and Language Teaching}

Progressivism in education finds significant allies in psycholinguistic and sociolinguistic analysis. Perhaps Krashen is the main protagonist of this new trend; he comes to the conclusion that it is very unlikely that focus on form will lead to the acquisition of language in communicative settings. Formal learning is not to be equated with «acquired knowledge» (acquisition). The former can only «monitor» performance, but never generates the latter. As a consequence, Krashen calls for a focus on meaning (internal build up through exposition to the language) as an efficient way to attain the acquisition of a foreign/second language and rejects formal teaching (through conscious understanding of the grammar involved and practice through drills and linguistically based exercises). «Comprehensible input» is the key in Krashen's theory. Meaning is, therefore, more important than form in the teaching situation. He names the «practical approach or method» for the teaching of languages the «natural method», no doubt with a clear reference to previous methodological developments in the history of language teaching (Gouin in the nineteenth century, Berlitz and the «Direct Method» in the twentieth century). He probably does so because his theory runs parallel-he believes-to the way we acquire language in a natural environment.

Krashen's «natural approach» is in direct opposition to usual practice in the classroom, especially in the school system, where the formal component (grammar) plays the starring role. Regarding grammar (taken here as the symbol for any kind of formal teaching/learning) the «input theory» implies not only the differentiation between learning and acquisition: it also states that «learning» may be a hindrance in achieving «acquisition» (which is the ultimate goal). Krashen's theory explains, at least partially, some of the facts observed in the process of learning languages. For example, why students are unable to apply a well «learned» (memorized) rule correctly, even after practicing it in sentences designed for such a purpose; why methods centred on the learning of the formal aspects of language are of little help in using the language learned in real communicative situations, etc. Learning does not become «acquisition» if it has not been internalized by the student. Krashen's views are representative of psychological insights applied to language teaching. He was widely read first in the USA and his popularity soon reached Europe. Communicative methodology, developing at that time on the basis of the notional-functional approach, could not but welcome this contribution: focus on meaning rather than on form and the stress put on the role of the learner as the main actor in the process (the only one that can «acquire through internalization of external materials to which he is exposed in a comprehensible way»), all this connects fully and directly with the basic assumptions underlying a communicative teaching of languages. We may quote here the words of Breen/Candlin/Waters to summarise the approach centred on meaning:

Rather than encourage learners to learn language in order to communicate, we may encourage leamers to communicate in order to develop their own learning. ...

Communication is achieved, in this view, through the practice of communication. In order to achieve the final goal, the process matters more than the techniques, the content learnt or the goal itself. 
At the moment communicative methodology is a complex issue: scholars, textboks authors and teachers do not always mean the same thing when they use the term. Some more time is still needed to clarify the field and decide which elements are most useful for the classroom. Theoretical explanations cannot be expected to be «translated» into practice directly. Meanwhile teachers are often worried by substantial contradictions between goals and techniques for attaining them; between innovations put forward by specialists and the requirements of official curricula and examinations; between the old and the new, in general; between what textbooks apparently offer and what they really allow you to do by means of the materials and activities they provide. A more practical and operative communicative methodology has still to be reached. On the other hand, the degree of complexity we may nowadays detect in this approach is the result of many contributions from different sciences, analyses and studies, a fact that also increases its richness and lays down the basis for a more balanced and efficient way of teaching and learning. In the above brief discussion of some issues we will, I hope, find the keys to a better understanding of a methodology that aims at the learning of languages with the purpose of communication in mind. A more detailed investigation of those issues would still be required to improve the practical applications teachers are waiting for.

\section{Works Cited}

Canale, M. «From Communicative Competence to Communicative Language Pedagogy.» Language and Communication. Eds. J. Richards and R. W. Schmidt. London: Longman, 1983.

and M. Swain. «Theoretical Bases of Communicative Approaches to Second Language Teaching and Testing.» Applied Linguistics 1.1 (1980): 1-47.

Candlin, C. N. «Communicative Language Teaching and the Debt to Pragmatics.» Semantics:

Theory and Application. Ed. C. Rameh. Georgetown University Round Table on Languages and Linguistics. Washington DC: Georgetown UP, 1976.

Dieuzeide, H. «Technologie éducative II: l'école de demain.» L'education 91 (1971).

Dubin, S. Course Design. Cambridge: Cambridge UP, 1986.

Gaonac'h, Daniel. Acquisition et utilization d'une langue étrangère. Paris: Hachette, 1990.

Gouin, François. The Art of Teaching and Studying Languages. Trans. H. and V. Bétis. London: George Philip, 1982.

Halliday, M. A. K. Explorations in the Functions of Language. London: Edward Arnold, 1973. Language as Social Semiotics. London: Edward Arnold, 1978.

A. McIntosch and P. Strevens. The Linguistic Sciences and Language Teaching. London: Longman, 1964.

Hamilton, D, D. Jenkins, C. King, B. McDonald and M. Parlett, eds. Beyond the Numbers Game. Basingstoke: McMillan Education, 1977.

Hanley, J. P., D. K. Whitelaw, E. W. Moo and A. S. Walter. Curiosity, Competence, Community, Man: A Course of Study, An Evaluation. Cambridge, MA: Educational Development Center, 1970.

Holec, H. Autonomy and Foreign Language Learning. Oxford: Pergamon, 1979.

Hymes, D. H. Language in Culture and Society: A Reader in Linguistics and Anthopology.

New York: Harper and Row, 1974. 
«On Communicative Competence.» 1971. Sociolinguistics: Selected Readings. Eds. J.

B. Pride and J. Holmes. Harmondsworth: Penguin Education, 1972.

Johnson, K. Communicative Syllabus Design and Methodology. Oxford: Pergamon, 1982.

Krashen, S. Principles and Practice in Second Language Learning. London: Pergamon, 1982. 1981. Second Language Acquisition and Second Language Learning. London: Pergamon, and T. D. Terrel. The Natural Approach. Language Acquisition in the Classroom. London: Pergamon, 1983.

Lyons, J. Introduction to Theoretical Linguistics. Cambridge: Cambridge UP, 1968.

Moirand, Sophie. Enseigner à communiquer en langue étrangère. Paris: Hachette, 1982.

Mumby, J. Communicative Syllabus Design. Cambridge: Cambridge UP, 1978.

Nunan, D. The Learner-Centred Curriculum. Cambridge: Cambridge UP, 1978.

Oskarsson, M. Approaches to Self-Assessment in Foreign Language Learning. Oxford: Pergamon, 1978.

Parlett, M. and D. Hamilton. «Evaluation as Illumination: A New Approach to the Study of Innovatory Programmes.»1972. Eds. Hamilton et al.

Peck, A. J. «Talking to Some Purpose (Choosing the Language-teaching Points of the Nuffield/Schools Council German Course).» Applications of Linguistics. Eds. G. E. Perren and J. L. M. Trim. Cambridge: Cambridge UP, 1969.

Pestalozzi, J. H. How Gertrude Teaches Her Children. Trans. Lucy E. Holland and Frances C. Turner. Syracuse, NY: C. W. Bardeen, 1898.

Prabhu, N. S. Second Language Pedagogy. Oxford: Oxford UP, 1987.

Richterich, E. and J. J. Chancerel. Identifying the Needs of Adults Learning a Foreign Language. Oxford: Pergamon, 1977.

Richterich, R. Case Studies in Identifying Language Needs. Oxford: Pergamon, 1983.

Rogers, C. R. Freedom to Learn. Columbus, Ohio: Merrill, 1969.

Sánchez, Aquilino. El método comunicativo y su aplicación a la clase de idiomas. Madrid: SGEL, 1987.

. La enseñanza de idiomas. Principios, problemas y métodos. Barcelona: Hora, 1982.

Schwartz, B. Permanent Education: Final Report CCC/EP (77). Strasbourg: Council of Europe, 1977. L'éducation demain. Paris: Aubier, 1973.

Stenhouse, L. An Introduction to Curriculum Research and Development in Action. London: Heineman, 1975.

Stern, H. H. Fundamental Concepts of Language Teaching. Oxford: Oxford UP, 1983.

Taba, H. Curriculum Development: Theory and Practice. New York: Harcourt, 1962.

Trim J. L. M. Some Possible Lines of Development of an Overall Structure for a European Unit-Credit Scheme for Foreign Language Learning by Adults. Strasburg: Council of Europe, 1978.

Trim J. L. M., R. Richterich, D. A. Wilkins and J. A. Van Ek. Systems Development in Adult Language Learning. Strasburg: Council of Europe, 1973.

Van Ek, J. A. The Threshold Level. Strasburg: Council of Europe, 1975.

Widdowson, H. G. Teaching Language as Communication. Oxford: Oxford UP, 1978.

Wilkins, D. A. Notional Syllabuses. London: Oxford UP, 1976. 